Titulo do Trabalho

\title{
MEMÓRIA E REPRESENTAÇÃO SOCIAL DAS ÁGUAS URBANAS DE PRESIDENTE PRUDENTE - SP
}

\author{
Nome do Autor (a) Principal
}

\section{Beatriz Fagundes}

Nome (s) do Orientador (a) (s)

Prof. Dr. Antônio Cezar Leal

Instituição ou Empresa

UNESP - Presidente Prudente - SP

Instituição (s) de Fomento

CNPq

E-mail de contato

beafagundes@yahoo.com.br

Palavras-chave

Águas urbanas. Memória. Representações Sociais.

\section{INTRODUÇÃO}

Nossa proposta de pesquisa surge a partir das reflexões que foram sendo construídas, durante nossa trajetória de estudo, envolvendo as relações entre a cidade, sua população e suas águas.

Desde os primeiros assentamentos humanos, a água foi de certa forma "dominada/integrada" na vida social, para atender as necessidades imediatas da população. Contemporaneamente, as transformações do espaço resultam um ambiente altamente modificado, constituído por "um sistema de 

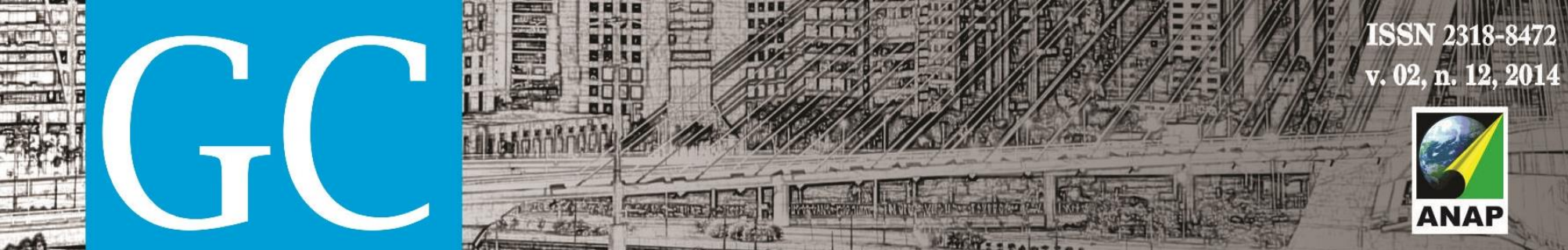

Revista Nacional de

Gerenciamento de Cidades

objetos cada vez mais artificiais, povoado por sistemas de ações igualmente imbuídos de artificialidade" (SANTOS, 2002, p. 63). Nesse ambiente, fatores naturais como vegetação, animais e, principalmente, cursos d'água, nascentes, lagos, têm sido gradativamente expulsos ou suprimidos da visibilidade urbana.

Um ambiente marcado pela presença da técnica e da ciência, onde o ser humano não precisa mais, necessariamente, se estabelecer próximo aos rios, mas pode reorganizar os seus lugares, manipulando os circuitos da água para qualquer lugar, como é o caso de uma rede de saneamento, que distribui a água e, depois de servida, as leve para bem longe de suas casas. Com a ajuda das técnicas o ser humano, confinou ou retificou em concreto os cursos d'água e, neste processo, produziu a sua atual morada dotada de infraestrutura, mas que também podem se tornar ambientes "insalubres e desumanos" (RIBEIRO, 2004, p. 165).

Frequentemente, verifica-se o desaparecimento dos cursos d'águas nas cidades. Ou a falta de cuidados com aqueles ainda não canalizados, ou seja, a presença constante de lixo e esgoto no seu leito faz com que a própria população demonstre certa rejeição a essas águas, o que tem levado a solicitarem ações imediatas do poder público no sentido de acabar com o problema, o que, muitas vezes, tem significado suprimir essas águas da paisagem (GHILARDI e DUARTE, 2006).

Geralmente, a retificação/canalização dos cursos d'água, representavam/am o papel de "controlar" as águas, muitas vezes consideradas ou divulgadas como alternativas para evitar epidemias e enchentes. Para Jorge (apud FIORAVANTI, 2013) os serviços realizados, para esses fins, foram ineficientes, pois, muitas epidemias poderiam ser evitadas, de outras formas, como o tratamento dos esgotos. E, as enchentes, "produto da própria urbanização", como afirma de forma enfática Seabra (2011), podem causar muitos prejuízos sociais, econômicos e até mesmo a morte.

Mas, estudos como os de Costa (2006) e Gorski (2010), têm confirmado que os cursos d'água, quando valorizados como um elemento 
sociais de antigos e novos moradores de Presidente Prudente em relação aos cursos d'água?

Assim, nosso desafio é buscar as respostas e trazer uma contribuição para a gestão pública municipal e aos moradores da cidade, para que Presidente Prudente possa vir a construir outra relação com os cursos d'água que ainda permanecem na sua paisagem, para que estes sejam incorporados à cidade e à vida da população de forma salutar, na possibilidade de ampliar a qualidade de vida.

Nesse sentido, consideramos pertinente reconstruir como ocorreu o processo de produção do espaço urbano de Presidente Prudente, recuperando paisagens antigas da cidade, para entender o destino das águas urbanas ${ }^{1}$ a partir do processo de expansão do espaço urbano.

\section{OBJETIVO GERAL}

Registrar e reconstruir as paisagens do passado da cidade de Presidente Prudente - SP, em que os cursos d'águas estavam mais presentes, para entender as relações que historicamente foram estabelecidas entre a cidade e suas águas, e quais as representações sociais contemporâneas, sobre as águas ainda presentes na paisagem urbana.

\section{OBJETIVOS ESPECÍFICOS}

Reconstruir a história de Presidente Prudente - SP a partir das relações entre a cidade, sua população e suas águas;

\footnotetext{
${ }^{1}$ Temos conhecimento, segundo Tucci (2008) que a definição dada para "águas urbanas" é todo o sistema de abastecimento de água e esgotos sanitários, a drenagem urbana e as inundações ribeirinhas. Porém nessa pesquisa as águas urbanas referem-se a todo curso d'água, nascentes, córregos ou rios que fazem parte do espaço urbano.
} 

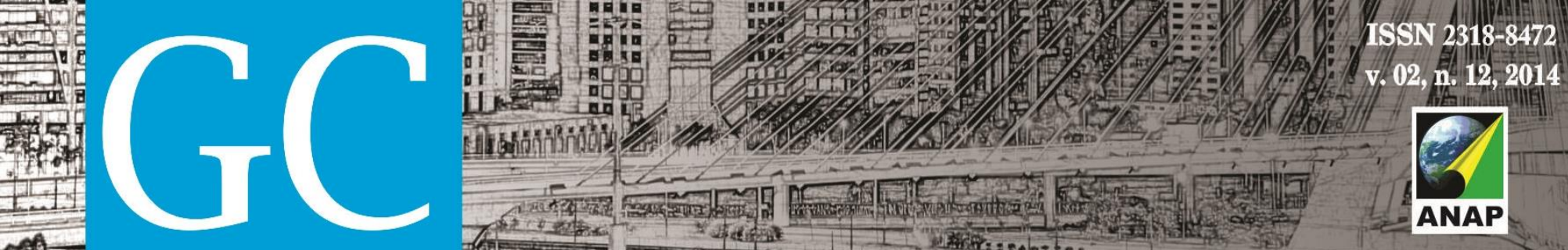

Revista Nacional de

Gerenciamento de Cidades

realizado entrevista com o/os responsável/is pelo planejamento ambiental e urbano e análise do plano diretor e ambiental do município.

Por outro lado, consideramos importante conhecer as representações sociais que a população tem hoje sobre os córregos urbanos ainda presentes na paisagem. Para isto, pensamos em delimitar algumas áreas mais recentes de expansão urbana nas bacias dos Rios do Peixe e Santo Anastácio, que estão incorporando novos córregos, para, por meio de entrevistas, identificarmos como tais córregos são vistos, quais as relações que a população estabelece com eles e o que pensam das formas como estão sendo incorporados à malha urbana, pelas estratégias de intervenção urbanística.

Para o levantamento das representações sociais, a base será seu debate no campo da Psicologia Social (SÁ, 1998, 2002, 2005), no qual as representações sociais são entendidas como elementos de comunicação, baseando-se, muitas vezes, em conceitos desenvolvidos em conversas. Compreender e explicar a construção do conhecimento leigo, os saberes do senso comum, é necessário, um modelo teórico, um conhecimento científico e isso é possível através da Teoria das Representações Sociais ${ }^{2}$ (SANTOS, 2005).

Segundo Sá (1998) a Teoria das Representações Sociais não privilegia nenhuma técnica de pesquisa em especial, possibilitando assim, que o/a pesquisador/a escolha aquelas consideradas como melhores para alcançar os resultados desejados. Desse modo, decidimos partir da seguinte consideração: As representações sociais, como elementos de comunicação, baseiam-se muitas vezes em conceitos desenvolvidos em conversas. A "conversação está no epicentro do nosso universo consensual porque ela molda e anima as Representações Sociais e assim Ihes dá vida própria" (MOSCOVICI, apud SPINK, 1995, p. 99). Por isso, daremos preferência na

\footnotetext{
${ }^{2}$ A Teoria das Representações Sociais ficou conhecida em 1961, através da obra La Psychanalyse: son image e son public desenvolvida pelo psicólogo social francês Serge Moscovici (1978 e 2003).
} 
pesquisa por conversas informais ${ }^{3}$ e formais ${ }^{4}$ para identificar as representações sociais em vigor acerca das águas urbanas.

O centro da pesquisa gira em torno de informações de natureza qualitativa.

A análise das entrevistas só será possível através das transcrições das narrativas ${ }^{5}$.

Serão exploradas formas de análise apropriadas para tais informações, como análise do discurso e as metodologias próprias empregadas pela Psicologia Social, no tratamento de representações sociais (SÁ, 1998, 2002, 2005) categorização das entrevistas, tabulação das entrevistas por assuntos, de modo a podermos comparar as diversas falas de diferentes sujeitos sociais.

Tudo isto nos permitirá ter acesso tanto à cidade do passado, quanto as representações atuais sobre os córregos urbanos em Presidente Prudente.

Outro instrumento de produção de informações é o diário de campo, para anotações, registro de observações e reflexões durante o desenvolvimento da pesquisa (QUEIROZ, 1991). Esta técnica de apoio será utilizada em todas as horas, principalmente em momentos nos quais surjam ideias repentinas e como locus de descrição das conversas informais com as pessoas.

\section{RESULTADO (S)}

\footnotetext{
${ }^{3}$ As entrevistas informais são utilizadas como técnica exploratória, na fase preparatória e formativa da pesquisa. Seu objetivo principal é esclarecer questões previamente definidas, que serão enfocadas em entrevistas posteriores. Já as formais são utilizadas para a coleta de informações, na fase informativa da pesquisa (COLOGNESE e MÉLO, 1998).

4 Já com categorias pré-formatadas.

${ }^{5}$ Transcrever as narrativas em plena e total conformidade com sua forma, em total identidade, sem nada que o modifique. É a fase em que, da fita gravada, se obtém um documento escrito (QUEIROZ, 1991).
} 
Revista Nacional de

Gerenciamento de Cidades

realizavam os passeios nos finais de semana. Os banhos de rio ao sair da escola. A pesca com os amigos. Até mesmo o batismo praticado por algumas religiões.

Defendemos que é preciso valorizar a presença dos cursos d'água na paisagem e buscar novas alternativas para os rios e córregos urbanos, que não seja seu desaparecimento, tanto da paisagem, quanto da memória social.

Acreditamos que a compreensão das relações que se dá entre a cidade, a população e seus rios representa uma possibilidade de contribuir para a construção de ambientes urbanos mais agradáveis e saudáveis.

\section{REFERÊNCIAS}

ABREU, D. S. Formação histórica de uma cidade pioneira paulista: Presidente Prudente. Presidente Prudente: Faculdade de Filosofia Ciências e Letras, 1972, 339p.

ALVES, A. O. Planejamento ambiental urbano na microbacia do córrego da Colônia Mineira - Presidente Prudente/SP. Dissertação (Mestrado em Geografia) - Programa de PósGraduação em Geografia da UNESP/Presidente Prudente. Presidente Prudente, 2004, 166p.

AMORIM, M. C. de C. T. Análise ambiental e qualidade de vida na cidade de Presidente Prudente/SP. São Paulo, 1993. 136p. Dissertação (Mestrado em Geografia) - Faculdade de Filosofia, Letras e Ciências Humanas, Universidade de São Paulo.

O clima urbano de Presidente Prudente/SP. São Paulo, 2000. 374p. Tese (Doutorado em Geografia) - Faculdade de Filosofia, Letras e Ciências Humanas, Universidade de São Paulo.

COLOGNESE, S. A.; MÉLO, J. L. B. de. A técnica de entrevista na pesquisa social. Cadernos de Sociologia, Porto Alegre, v. 9, 1998. p. 143-159.

COSTA, L. M. S. A. (org.) Rios e paisagens urbanas em cidades brasileiras. Rio de Janeiro: PROURB - FAU - UFRJ, 2006. 190 p.

FIORAVANTI, C. Entre paredes de concreto. Revista Pesquisa Fapesp. Volume nํㅡ 214, p. 16-25, dez. 2013.

GHILARDI, A. S.; DUARTE, C. R. DE S. Ribeirão Preto: os valores naturais e culturais de suas paisagens urbanas. In: COSTA, L. M. S. A. (org.) Rios e paisagens urbanas em cidades brasileiras. Rio de Janeiro: PROURB - FAU - UFRJ, 2006. p. 95 - 119.

GORSKI, M. C. B. Rios e cidades: ruptura e reconciliação. São Paulo. Editora Senac São Paulo, 2010. 300 p. 
Revista Nacional de

Gerenciamento de Cidades

HORA, M. L. F. O Programa CURA III em Presidente Prudente: uma porta para a cidade? Presidente Prudente, 1997. Dissertação (Mestrado em Geografia) - Programa de PósGraduação em Geografia da UNESP. Presidente Prudente.

IKUTA, F. A. A cidade e as águas: a expansão territorial urbana e a ocupação dos fundos de vales em Presidente Prudente - SP. Dissertação (Mestrado em Geografia) - Programa de PósGraduação em Geografia da UNESP. Presidente Prudente, 2003.

KURAK, M. Atualização da base digital de dados espaciais e monitoramento do crescimento urbano de Presidente Prudente. Presidente Prudente, 2000. Dissertação (Mestrado em Ciências Cartográficas) - Programa de Pós-Graduação em Ciências Cartográficas da UNESP. Presidente Prudente.

LEAL, A. C. et al. Presidente Prudente: expansão territorial urbana e a ocupação dos fundos de vales. Presidente Prudente: FCT/UNESP, 1999. (Relatório de Pesquisa do Projeto de Integração Disciplinar - 1998).

LEITE, J. F. A Alta Sorocabana e o espaço polarizado de Presidente Prudente. Presidente Prudente, 1972. Tese (Doutorado em Geografia) - Programa de Pós-Graduação em Geografia da UNESP. Presidente Prudente.

MAY, T. Pesquisa Social: questões, métodos e processos. $3^{a}$ ed. Porto Alegre: Artmed, 2004.

MARACCI, M. T. O movimento por moradia e políticas de estado no contexto da produção do espaço-território urbano em Presidente Prudente. Presidente Prudente, 1999. Dissertação (Mestrado em Geografia) - Programa de Pós-Graduação em Geografia da UNESP. Presidente Prudente. 120p.

MARISCO, L. M. O. Contribuição ao estudo do planejamento municipal no Brasil: o plano diretor de desenvolvimento integrado de Presidente Prudente. Presidente Prudente, 1997. Dissertação (Mestrado em Geografia), Programa de Pós-Graduação em Geografia da UNESP.

MELAZZO, E. S. Mercado imobiliário, expansão territorial e transformações intraurbanas: o caso de Presidente Prudente-SP. Rio de Janeiro, 1993. Dissertação (Mestrado) IPPUR - Universidade Federal do Rio de Janeiro, 133p.

MOSCOVICI, S.. A representação social da psicanálise. Rio de Janeiro: Zahar, 1978. 291p.

Vozes, 2003. 404p.

Representações sociais: investigações em psicologia social. Petrópolis, RJ:

QUEIROZ, M. I. P. de. Variações sobre a técnica de gravador no registro da informação viva. São Paulo: T.A. Queiroz, 1991. 129 p.

RIBEIRO, W. C. Gestão das águas metropolitanas. In: CARLOS, A. F.; OLIVEIRA, A. U. de. (org.). Geografias de São Paulo: A metrópole do século XXI. São Paulo, SP: Editora Contexto, 2004. p. $165-182$.

SÁ, C. P. de. A construção do objeto de pesquisa em Representações Sociais. Editora: EdUERJ, Rio de Janeiro: 1998. 110 p. 
